\title{
Identify and Prioritize the Key Success Factors in the Establishment of Crowdsourced Systems
}

\author{
Ali Bonyadi Naeini ${ }^{1} \&$ Amin Reza Atashkar ${ }^{2}$ \\ ${ }^{1}$ Assistant Professor, Iran University of Science and Technology (IUST), Iran \\ ${ }^{2}$ MSc. of Technology Management- Iran University of Science and Technology (IUST), Iran \\ Correspondence: Ali Bonyadi Naeini, Assistant Professor, Iran University of Science and Technology (IUST), \\ Iran. E-mail: bonyadi@iust.ac.ir/aminmailid@gmail.com
}

Received: March 12, 2016

Accepted: March 25, 2016

Online Published: April 10, 2016

doi:10.5539/mas.v10n6p105

URL: http://dx.doi.org/10.5539/mas.v10n6p105

\begin{abstract}
This study sought to determine the key factors affecting the success of crowdsourcing. In this study, both exploratory and confirmatory examined and finally, structural equation modeling was used to validate the proposed model. In this study, we tried to investigate key elements in the organization, the conceptual framework for the relationship between these factors be addressed. This study aimed to evaluate the identification and prioritization of the key success factors in the establishment of crowdsourcing was used in the automotive industry and purpose of the survey and questionnaires were used. The population in this study, car industry executives. As expressed in the research evaluation experts has been used. To investigate the relationship for each of the relationships shown in the model, the model analysis of Amos Software was used. The findings of this research to the development of crowdsourcing to help organizations, because it has tried to provide empirical evidence and in accordance with the terms of the Iranian executive model, the model organizations in order to be able to managers and planners given the circumstances and the amount of resources and organizational priorities of the development and implementation of projects of crowdsourcing to take better decisions.
\end{abstract}

Keywords: crowdsourcing, automotive industry, Amos Software, outsourcing

\section{Introduction}

Outsourcing as a tool for development organizations to improve efficiency in the form of downsizing in recent years has been of interest to managers and directors of organizations in different forms has been implemented. Outsourcing as a tool for simple and economic performance is increasingly more applications. If we want to tangibly define outsourcing can be handed off some of an institution, to do, to another institution, called outsourcing (Hans, 2000). The term crowdsourcing is a combination of two words crowd and outsourcing. So crowdsourcing means is outsourcing to the crowd. Crowdsourcing is a form of outsourcing, but not specific to companies or organizations but also to the people through the public call for the vast majority of the Internet. Crowdsourcing business model is emerging as a new focus on partnerships whose population in activities such as problem solving, development of concepts such as participation in the ideas, the innovation, production and servicing processes that have a direct impact on product quality, loyalty and customer satisfaction (Bios, 2010). Crowdsourcing could be on the agenda of businesses, some non-core tasks to outside the organization to achieve greater efficiency and effectiveness. With the advent of outsourcing non-core functions of your organization able to transfer some out of the organization to achieve greater efficiency and effectiveness. Crowdsourcing is not limited to solving the problem and not the production of content (Shank, 2009). Business model, "crowdsourcing" focusing on the voluntary participation of the population to produce innovative products (Frank, 2006). The aim of this study was to help managers make effective use of crowdsourcing technology in society and industry, expressed greater access to information and the cost of diminishing the means of production and the latest advances emergence of online communities where people organize online crowdsourcing systems, construction of human social system that provides interaction between man and the relationship between humans and technology in the workplace. In this study, we sought to answer the following question, what are the key elements of crowdsourcing in the automotive industry? What is the relationship between agents have been counted? And how to prioritize key success factors? 


\section{Theoretical Foundations}

Today's business world characterized by the accelerating changes of all is to know that the chance of any rest. Organizations to fundamentally change and do not like to organizations yesterday. Among the changes in the structure and behavior of organizations, networks of their activities (Alvarado, 2001). Resources from outside the organization's planned activities in the planned activities, the use of other services and outsourcing all express a concept. The transfer of some activities to outside organizations. In today's organizations profitability, reduce costs, competition, quality, expertise, speed etc. of the critical issues for the survival of companies and organizations to reach their goals (Surowiecki, 2004). What is certain is that, in the nature of the media, there is a community of users and surely the question arises how this community for organizational and commercial activities that are all in the process of winning. This is where the need to delve into the concept of crowdsourcing (Platts, 2002). Population serves as the beginning of crowdsourcing. In the process of crowdsourcing normally order the recall of the population, crowdsourcing is the beginning of operations, but in reverse crowdsourcing, this "crowd" in the role of initiator and target appear crowdsourcing, crowdsourcing function has been improved to the point of physical products. This means that the input received in the framework of the population, the range of products and applications such as data and content beyond abstract and can also lead to the production of physical goods (Bhutta, 2002). Crowdsourcing is one of the ways to bypass traditional corporate boundaries, and manipulation of ideas have been developed to meet the needs of customers and users organizations (Howe, 2006). Brabham view of crowdsourcing a strategic model to attract people interested and motivated people able to deliver superior solutions qualitatively and quantitatively compared with business as usual can do what (Lakhal, 2001) is defined. One of the ideas discussed today the term crowdsourcing or crowd raised by Mr Howe in 2006 and could be on the agenda of businesses (Beth Simone, 2009) and the reasons for the emergence of crowdsourcing of view, people in leisure time or times when they are not considered to be part of a greater opportunity to do things that leads to economic production are found. The Industrial Revolution led to much of what has already been human, family and social groups do today was done by the firm and, as Toffler predicted consumers will not remain passive and turned to prosumer (Parvizian, 2006) Last development is the emergence of online communities that organize online population (Karimi, 2004). Crowdsourcing means the way in which the activity performed by an employee or contractor was done in traditional terms, now a collector or an unknown network, and generally a lot of people, to be deposited Call (Howe, 2007) . Hayek was stated in 1945 that: Virtually every individual to some extent has priority over others because of its unique information that may be useful to use them can be useful, but only if that decision or the individual is granted or has he taken active participation (Hayek, 1945). The division of labor may seem shabby these days as a term and certainly this ancient concept in economics dating back about 200 years, supplier of post-industrial age will not be a new miracle but some strategies such as outsourcing can be considered due to the use of this concept (Welch, 1992). In simple terms, crowdsourcing: Outsourcing is the same but with the difference that instead of one person or set to a sum deposited (Alonso, O., Rose, DE, \& Stewart, 2008). Outsourcing is the transfer of all or part of an organization responsible for performing a specific task to an individual, group or professional organization, while also enabling cost reduction possibility of superior quality (Balachandra, 1997). Outsourcing process, the processes that the organization needs for its management system and its implementation process has been assigned to the external (Beth Simone, 2009). In many cases, the outsourcing, the right decisions and factors of production be transferred to other organizations (Keshtkar, 2010). The purpose of outsourcing small size enterprises, have more flexibility in creating rapid changes, use of facilities and expertise acceptor (external companies) (Shahidi, 2007). Crowdsourcing, crowdfunding, two words that are used today in many countries is on the agenda of businesses and entrepreneurs. Crowdsourcing by combining two words mean outsourcing the required resources to a range of people with statistically significant scale. (Finn, 2002). Crowdsourcing is one of the most important trends that fundamental look at the way in which business, governments and humanitarian organizations to look at changing the mobile Internet market (Habibi, 2011). The key factor in the crowd that comes from the crowd, is the principle of collective wisdom (Brabham, 2008). Today, outsourcing is a good way for organizations to reduce costs, focus on core processes and capabilities, improve services, upgrade skills, reduce time to commercialization of ideas and increased competitive advantage for organizations. In our country, often from the perspective of organizations that want to outsource their work to this point has been noted. While it can be outsourced services from the perspective of the organization that is going to look into the issue. In this case, given the available opportunities for outsourcing services by regional and international companies in the regional markets, the importance is much greater (Lau, 2000).

\section{Research Methodology}

This study sought to determine the key factors affecting the success of crowdsourcing. According to the existing 
relationships we will use the following model.

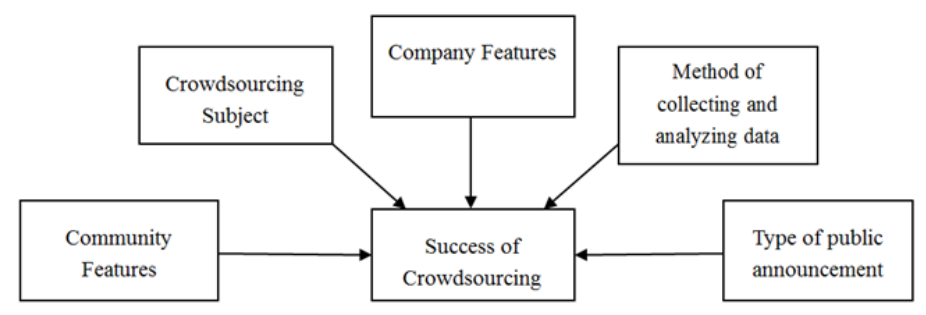

Figure 1. Research Model

In this research, since the study is to identify the key success factors of the situation and providing solutions for the implementation of the research conducted is a descriptive - survey study. Also, since the study was conducted in a dynamic organization and the results can be used to solve practical problems of implementation, is an applied research. Research questions to determine the conditions described, structure and implementation requirements of key success factors have been proposed. In this research to study the distribution characteristics of crowdsourcing occurs. So, scrolling through the library documents and websites on the Internet is done randomly and the survey was conducted. Statistical society consists of a collection of individuals or entities that have at least one common trait. The population must be comprehensive definition. That definition should be expressed so that the point of view of time and space to include all the study subjects and also due to the inclusion of units that should be addressed in the study is prevented. The population of this study, managers of auto companies in the country. The number of people on the basis of this definition, 90 is considered. To test the conceptual model of structural equation modeling and path analysis used. Amos software will be used for this purpose. Amos software, software for structural equation modeling, structural equation modeling that offers graphical manner. Path analysis for the first time by the Seoul Wright developed, spread of regression method and in fact, the use of multiple regression in relation to the development of scientific models is obvious. Concepts for the analysis of the main characteristics of the graph in the best way possible causal connections between variables reveals that, explained. To produce the graph, the names of variables to write and draw the arrow for each variable to another variable that affects believe in it.

\section{Results}

Confirmatory factor analysis variables and exploratory factor analysis (EFA)

Structural Equation Modeling or particular structural models (of course) by AMOS software was used. Normal distribution of variables in the regression, the default is the most important due to non-parametric test Kolmogorov - Smirnov, confirmed the assumption of all the variables. Figure 2 shows the results of using structural equation modeling (Path Analysis) show. This figure, estimating the coefficients of the standard model shows that the standardized coefficients (beta) is multiple regression analysis. In this model the variables and factors, has been named as Figure 6:

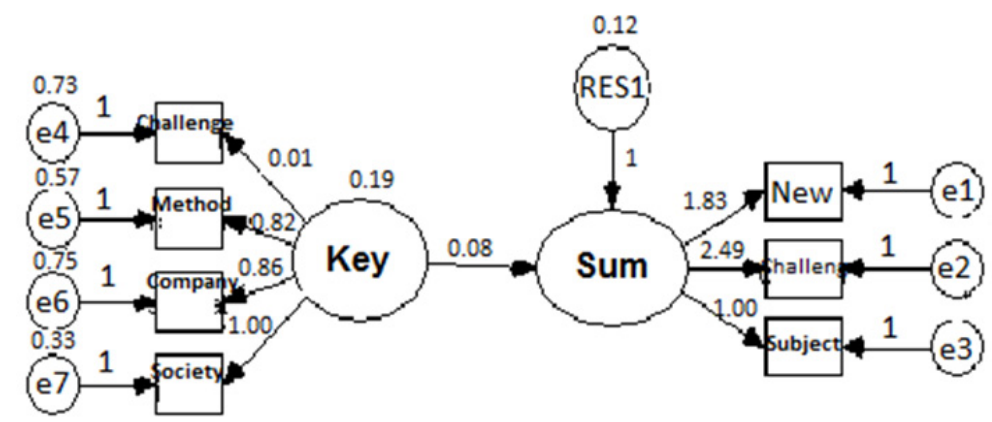

Figure 2. Standardized coefficients related to structural equation modeling (Path Analysis) 
The standardized coefficients, to compare the work of each of the model components used. The absolute value of the coefficient is larger, which means that the impact of the independent variable on the dependent variable is greater. The direct effects Amos path analysis of statistic t, to assess the significance of the coefficients used in the model. Since the default significance level, 0.05 times the fruit, it will be significant coefficients obtained if the corresponding value is greater than 1.96 or smaller than -1.96 . As the absolute value is greater than 1.96 , indicating the impact of the independent variable on the dependent variable will be more and more powerful. As you can see, crowdsourcing and key success factors are significant variables. Indicators of well-being in the path analysis model, chi-square test and are RMSEA index. The best indicator, the ratio of the degree of freedom chi-square statistic, ie $\frac{\chi^{2}}{d f}$. As this ratio is less than 3 model fit and a better fit. RMSEA index, the mean squared errors of the model. The index is based on the errors made. Limit the index is 0.8. If RMSEA value below 0.8 is acceptable and if it is below 0.5 is very good.

Table 1. Model fit indices in the path analysis

\begin{tabular}{|c|c|c|c|}
\hline \multirow{2}{*}{ Mean square error of RMSE model } & \multicolumn{2}{|c|}{ Chi-square test } & \multirow{2}{*}{$\chi^{2}$} \\
\cline { 2 - 3 } & Degrees of freedom (Df) & $\begin{array}{c}\text { Statistics value of } \\
\chi^{2}\end{array}$ \\
\hline 0.537 & 6 & 502.232 & 83.705 \\
\hline
\end{tabular}

Since the value of RMSEA index (mean square error model) of 0.8 or less is acceptable model fit. This implies that the relationship between the variables set on the basis of theoretical research, is reasonable. To evaluate the proposed framework, with confirmatory factor analysis to examine the relationship between questions (observed variables) each structure and structures (agent, factor or latent variable) will be discussed. In fact, test measurement models to ensure that the structures are used for the measurement is done. Standardized regression coefficients (path), squared multiple correlation, which represents the ratio of the observed variance variable by the latent variable and as indicators of goodness of fit is calculated for each of the key factors.

Table 2. Regression Weights: (Group number 1 - Default model)

\begin{tabular}{llllllll}
\hline & & & Estimate & S.E. & C.R. & P & Label \\
\hline Sum & $<---$ & Key & .080 & .038 & 2.090 & .037 & par_6 \\
Subject & $<--$ & Sum & 1.000 & & & & \\
Challenge & $<---$ & Sum & 2.490 & .500 & 4.976 & $* * *$ & par_1 \\
New & $<---$ & Sum & 1.834 & .278 & 6.597 & $* * *$ & par_2 \\
Society & $<--$ & Key & 1.000 & & & & \\
Company & $<---$ & Key & 2.855 & .775 & 3.684 & $* * *$ & par_3 \\
Method & $<---$ & Key & .818 & .150 & 5.466 & $* * *$ & par_4 \\
General & $<---$ & Key & .011 & .117 & .094 & .925 & par_5 \\
\hline
\end{tabular}

Table 3. Standardized Regression Weights: (Group number 1 - Default model)

\begin{tabular}{ll|ll}
\hline & & & Estimate \\
\hline Sum & $<---$ & Key & .096 \\
Subject & $<---$ & Sum & .526 \\
Challenge & $<---$ & Sum & 1.221 \\
\hline New & $<---$ & Sum & .719 \\
Society & $<---$ & Key & .594 \\
Company & $<---$ & Key & 1.411 \\
Method & $<---$ & Key & .422 \\
General & $<---$ & Key & .006 \\
\hline
\end{tabular}


It should be noted that the significance of P-Value is determined by calculating the path and path in this study only considered significant. In addition to being fit model to measure the degree of freedom chi-square $\left(\chi^{2} / \mathrm{df}\right)$ comparative fit index, index-adjusted index fitness waste and root mean square error of approximation is used to estimate variance. Favorable than $\chi^{2} /$ df less than 3, the amount of more than 0.9 to GFI, CFI, AGFI close to zero for RMR and less than 0.1 for RMSEA.

Table 4. RMR, GFI

\begin{tabular}{lllll}
\hline Model & RMR & GFI & AGFI & PGFI \\
\hline Default model & .151 & .731 & .421 & .339 \\
Saturated model & .000 & 1.000 & & \\
Independence model & .250 & .460 & .281 & .345 \\
\hline
\end{tabular}

Table 5. RMSEA

\begin{tabular}{lllll}
\hline Model & RMSEA & LO 90 & HI 90 & PCLOSE \\
\hline Default model & .357 & .311 & .404 & .000 \\
Independence model & .537 & .502 & .574 & .000 \\
\hline
\end{tabular}

The results indicate favorable structures and fitting indicators measuring key success factors also show that measurement models, as well as the data did not cover.

Correlation matrix of variables

Table 6. Implied Correlations (Group number 1 - Default model)

\begin{tabular}{llllllll}
\hline & General & Method & Company & Society & New & Challenge & Subject \\
\hline General & 1.000 & & & & & & \\
Method & .002 & 1.000 & & & & & \\
Company & .008 & .595 & 1.000 & & & & \\
Society & .003 & .251 & .839 & 1.000 & & & \\
New & .000 & .029 & .098 & .041 & 1.000 & & \\
Challenge & .001 & .050 & .166 & .070 & .878 & 1.000 & \\
Subject & .000 & .021 & .072 & .030 & .379 & .643 & 1.000 \\
\hline
\end{tabular}

With regard to the relationship between key performance factors and crowdsourcing this variable into the regression equation and to determine the predictive power of each of the following measures key performance factors regression analysis were used. This means that aspects of key performance factors as independent variables and the dependent variables were entered into the regression equation as crowdsourcing.

Table 7. Regression Weights: (Group number 1 - Default model)

\begin{tabular}{llllllll}
\hline & & & Estimate & S.E. & C.R. & P & Label \\
\hline Sum & $<---$ & Key & .080 & .038 & 2.090 & .037 & par_6 \\
Subject & $<---$ & Sum & 1.000 & & & & \\
Challenge & $<---$ & Sum & 2.490 & .500 & 4.976 & $* * *$ & par_1 \\
New & $<---$ & Sum & 1.834 & .278 & 6.597 & $* * *$ & par_2 \\
Society & $<---$ & Key & 1.000 & & & & \\
Company & $<---$ & Key & 2.855 & .775 & 3.684 & $* * *$ & par_3 \\
Method & $<---$ & Key & .818 & .150 & 5.466 & $* * *$ & par4 \\
General & $<---$ & Key & .011 & .117 & .094 & .925 & par_5 \\
\hline
\end{tabular}

In order to rank the four key elements of the Friedman test was used variables that include rankings with four different types of public gathering and analyzing data, enterprise features, characteristics of the community. Hypothesis test: The current status of the four variables (type of public announcement, the method of collecting and analyzing data, enterprise features, characteristics of the population), there are significant differences in 
terms of priority. It can be formulated statistical assumptions, including: H0, between the four variables (type of public announcement, the method of collecting and analyzing data, enterprise features, characteristics of the population), there were no significant differences in terms of priorities and $1 \mathrm{H}$, between the four variables (with the type of public gathering and data analysis, enterprise features, characteristics of the population) there were no significant differences in terms of priorities, is. SPSS output, including two table. The first significant Friedman test for four variables are presented in Table II average rating of 4 variables is presented. According to SPSS output significant value (sig) was more significant level of 0.05 or more of the standard $(\alpha=5 \%)$. This assumption is confirmed $0 \mathrm{H} 95 \%$. Therefore we can say that the current situation of the four variables (type of public announcement, the method of collecting and analyzing data, enterprise features, characteristics of the population), there is no significant difference of priorities intended. The following table is visible.

Table 8. Significance of Friedman test for the four key success factors

\begin{tabular}{ll}
\hline Calculated values & Statistics indices \\
\hline 153 & Number \\
7.807 & $\chi^{2}$ \\
4 & Degrees of freedom \\
0.099 & Significant number (sig) \\
\hline
\end{tabular}

Table 9. Average rating in Friedman test

\begin{tabular}{ll}
\hline $\begin{array}{l}\text { Ranking of four variables: the type of public announcement, } \\
\text { the method of collecting and analyzing data, enterprise }\end{array}$ & \\
feature, community feature & 3.15 \\
\hline Type of public announcement & 3.15 \\
Method of collecting and analyzing data & 3.09 \\
Company Feature & 2.82 \\
\hline Community Feature &
\end{tabular}

\section{Conclusion}

In this study, we tried to investigate key elements in the organization is required to provide a conceptual framework for the relationship between these factors and statistical analyzes to be paid to the relationship and prove hypotheses. Given the multiple dimensions of the key success factors such as the characteristics of this model. The findings contribute to the development of crowdsourcing in organizations, it has tried to provide empirical evidence and in accordance with the terms of the Iranian executive model, a model of the organization's managers and planners so that they can, given the circumstances and the amount of resources and organizational priorities of the development and implementation of projects of crowdsourcing make better decisions.

\section{References}

Bayus, B. (2010). Crowdsourcing New Products Over Time.

Schenk, E., \& Guittard, C. (2009). Crowdsourcing: What can be outsourced to the Crowd, and Why? Workshop on Open Source Innovation, Strasbourg, France.

Franke, N., von Hippel, E., \& Schreier, M. (2006). Finding Commercially Attractive User Innovations: A Test of Lead-User Theory. Journal of Product Innovation Management, 23(4), 301-315.

Howe, J. (2006). The Rise of Crowdsourcing. Wired, 14(6).

Beth, S. N. (2009). Wiki Government: How Technology Can Make Government Better ‘Democracy Stronger and Citizens More Powerful. Washington.

Keshtkar, M., Pishvaei, M., \& Mohammadi, A. (2010). Crowdsourced driving new business. Industrial Management Institute.

Shahidi, F., Mohammadian, A., \& Yavari, A. (2007). Systematic model to determine the strategy of outsourcing activities. Second International Conference on Strategic Management.

Habibi, H. (2011). The use of crowdsourcing for the commercialization of ideas, products and services businesses. Tehran University. Master's thesis. 
Brabham, D. (2008). Moving the Crowd at iStockphoto: The Composition of the Crowd and Motivations for Participation in a Crowdsourcing application. First Monday, 13(6).

Howe, J. (2007). The Rise of Crowdsourcing. Wired, 14(6).

Christian, H. P., \& Hans, P. (2000). Inter-Organizational Logistics systems in flexible production networks. International Journal of Physical Distribution \& Logistics Management, 30(5).

Alvarado, Y. U., \& Kotzab, H. (2001). Supply Chain Management. The Integration of Logistics Ana Marketing. Industrial Marketing Management.

Platts, K. W., Probert, D. R., \& Canez, L. (2002). Make vs. buy decisions: A process incorporating multi-attribute decision-making. International Journal of Production Economics, 77(3), 247-257,

Parvizian, K., \& Dehghan, N. (2006). Strategic outsourcing and venture capital in the value chain. The second national conference on venture capital.

Welch, J. A., \& Nayak, P. R. (1992). Strategic sourcing: A progressive approach to the make-or-buy. The Academy of Management Executive, 6(1), 23-3.

Alonso, O., Rose, D. E., \& Stewart, B. (2008). Crowdsourcing for relevance evaluation. ACM SIGIR, 15-9.

Balachandra, R., \& Friar, J. (1997). Factors for Success in R\&D Projects and New Product Innovation: A Contextual Framework. IEEE Transactions on Engineering Management, 44, 276-87.

Fine, C., Vardan, R., Pethick, R., \& El-Hout, J. (2002). Moving a Slow-Clock speed Business into the Fast Lane: Strategic Sourcing Lessons from Value Chain Redesign in the Automotive Industry" Sloan Management Review.

Lakhal, S. (2001). On the optimization of supply chain networking decisions. European Journal of Operational Research, 129, 259-270.

Chris, F. (2000). Outsourcing or increasing risks? Balance Sheet, 8(2), $34-37$.

Lau, H. C. W., \& Lee, W. B. (2000). On a responsive supply chain information system. International Journal of Physical Distribution \& Logistics Management.

Surowiecki, J. (2004). The Wisdom of Crowds: Why the Many are Smarter than the Few and How Collective. Wisdom Shapes Business, Economies, Societies, and Nations, Doubleday.

Hayek, F. (1945). The Use of Knowledge in Society. American Economic Review, 35, 519-530.

Karimi, G. M. (2004). Outsourcing decision model (build / buy). Fourth International Conference on Quality Management.

Bhutta, K. S., \& Hug, F. (2002). Supplier selection problem: A comparison of the total cost of ownership and analytic hierarchy process approaches. Supply Chain Management: An International Journal, 7(3),126-135.

\section{Copyrights}

Copyright for this article is retained by the author(s), with first publication rights granted to the journal.

This is an open-access article distributed under the terms and conditions of the Creative Commons Attribution license (http://creativecommons.org/licenses/by/3.0/). 